University of Wollongong

Research Online

Australian Institute for Innovative Materials -

Papers

Australian Institute for Innovative Materials

$1-1-2014$

Pressure induced magneto-structural phase transitions in layered RMn2X2 compounds (invited)

Shane Kennedy

ANSTO

Jianli Wang

University of Wollongong, jianli@uow.edu.au

Stewart Campbell

University of New South Wales, stewart.campbell@adfa.edu.au

Michael Hofmann

Technische Universitat Munchen

S X. Dou

University of Wollongong, shi@uow.edu.au

Follow this and additional works at: https://ro.uow.edu.au/aiimpapers

Part of the Engineering Commons, and the Physical Sciences and Mathematics Commons

Research Online is the open access institutional repository for the University of Wollongong. For further information contact the UOW Library: research-pubs@uow.edu.au 


\title{
Pressure induced magneto-structural phase transitions in layered RMn2X2 compounds (invited)
}

\begin{abstract}
We have studied a range of pseudo-ternaries derived from the parent compound PrMn2 Ge 2, substituting for each constituent element with a smaller one to contract the lattice. This enables us to observe the magneto-elastic transitions that occur as the $\mathrm{Mn}-\mathrm{Mn}$ nearest neighbour distance is reduced and to assess the role of Pr on the magnetism. Here, we report on the PrMn2 Ge 2-xSix, Pr1-xYxMn2 Ge 2, and PrMn2-xFex Ge 2 systems. The pressure produced by chemical substitution in these pseudo-ternaries is inherently non-uniform, with local pressure variations dependent on the local atomic distribution. We find that concentrated chemical substitution on the R or X site (e.g., in $\operatorname{Pr} 0.5$ Y $0.5 \mathrm{Mn} 2 \mathrm{Ge} 2$ and $\operatorname{PrMn} 2 \mathrm{Ge}$ $0.8 \mathrm{Si}$ 1. 2) can produce a separation into two distinct magnetic phases, canted ferromagnetic and canted antiferromagnetic, with a commensurate phase gap in the crystalline lattice. This phase gap is a consequence of the combination of phase separation and spontaneous magnetostriction, which is positive on transition to the canted ferromagnetic phase and negative on transition to the canted antiferromagnetic phase. Our results show that co-existence of canted ferromagnetic and antiferromagnetic phases depends on chemical pressure from the rare earth and metalloid sites, on local lattice strain distributions and on applied magnetic field. We demonstrate that the effects of chemical pressure bear close resemblance to those of mechanical pressure on the parent compound.
\end{abstract}

\section{Keywords}

compounds, rmn2x2, layered, transitions, invited, phase, pressure, structural, magneto, induced

\section{Disciplines}

Engineering | Physical Sciences and Mathematics

\section{Publication Details}

Kennedy, S., Wang, J., Campbell, S., Hofmann, M. \& Dou, S. (2014). Pressure induced magneto-structural phase transitions in layered RMn2X2 compounds (invited). Journal of Applied Physics, 115 (17), 172617-1-172617-6. 


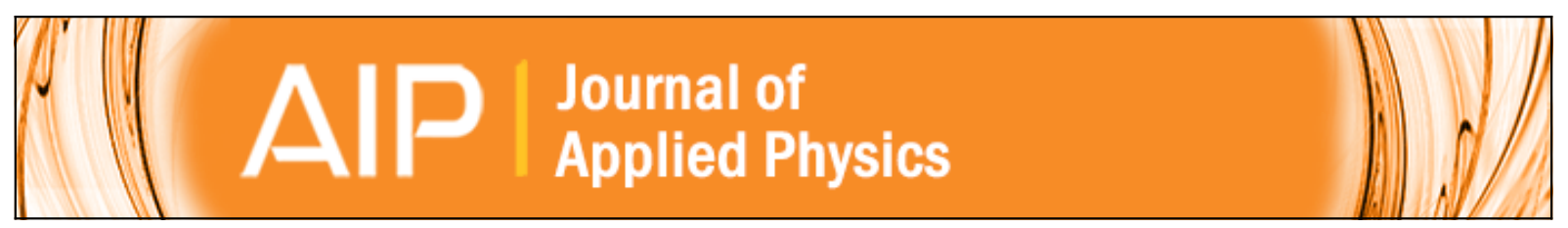

\section{Pressure induced magneto-structural phase transitions in layered RMn 2 X 2 compounds (invited)}

Shane Kennedy, Jianli Wang, Stewart Campbell, Michael Hofmann, and Shixue Dou

Citation: Journal of Applied Physics 115, 172617 (2014); doi: 10.1063/1.4870582

View online: http://dx.doi.org/10.1063/1.4870582

View Table of Contents: http://scitation.aip.org/content/aip/journal/jap/115/17?ver=pdfcov

Published by the AIP Publishing

\section{Articles you may be interested in}

Magnetoelastic coupling induced magnetic anisotropy in Co2(Fe/Mn)Si thin films

Appl. Phys. Lett. 104, 022402 (2014); 10.1063/1.4861777

The tunable magnetostructural transition in MnNiSi-FeNiGe system

Appl. Phys. Lett. 103, 132411 (2013); 10.1063/1.4823510

Magnetostructural phase transitions and magnetocaloric effects in MnNiGe1xAlx

Appl. Phys. Lett. 100, 052404 (2012); 10.1063/1.3681798

Re-entrant ferromagnet $\operatorname{Pr} \mathrm{Mn} 2 \mathrm{Ge} 0.8 \mathrm{Si} 1.2$ : Magnetocaloric effect

J. Appl. Phys. 105, 07A909 (2009); 10.1063/1.3059610

Magnetic phase transitions in ( $\mathrm{Tb}, \mathrm{Y}) \mathrm{Mn} 2 \mathrm{M} 2$ ( $\mathrm{M}=\mathrm{Ge}$ and $\mathrm{Si}$ ) systems

J. Appl. Phys. 93, 8185 (2003); 10.1063/1.1541652

\section{AlP Re-register for Table of Content Alerts}




\title{
Pressure induced magneto-structural phase transitions in layered $R M n_{2} X_{2}$ compounds (invited)
}

\author{
Shane Kennedy, ${ }^{1, a)}$ Jianli Wang, ${ }^{1,2}$ Stewart Campbell, ${ }^{3}$ Michael Hofmann, ${ }^{4}$ \\ and Shixue Dou ${ }^{2}$ \\ ${ }^{1}$ The Bragg Institute, Australian Nuclear Science and Technology Organisation, Lucas Heights, NSW, \\ Australia \\ ${ }^{2}$ Institute for Superconductivity and Electronic Materials, University of Wollongong, Wollongong, NSW, \\ Australia \\ ${ }^{3}$ School of Physical, Environmental and Mathematical Sciences, University of New South Wales, Canberra, \\ ACT, Australia \\ ${ }^{4}$ Forschungs-Neutronenquelle Heinz Maier-Leibnitz, Technische Universität München, Garching, Germany
}

(Presented 7 November 2013; received 23 September 2013; accepted 29 October 2013; published online 15 April 2014)

\begin{abstract}
We have studied a range of pseudo-ternaries derived from the parent compound $\mathrm{PrMn}_{2} \mathrm{Ge}_{2}$, substituting for each constituent element with a smaller one to contract the lattice. This enables us to observe the magneto-elastic transitions that occur as the Mn-Mn nearest neighbour distance is reduced and to assess the role of $\operatorname{Pr}$ on the magnetism. Here, we report on the $\operatorname{PrMn}_{2} \mathrm{Ge}_{2-x} \mathrm{Si}_{\mathrm{x}}$, $\operatorname{Pr}_{1-\mathrm{x}} \mathrm{Y}_{\mathrm{x}} \mathrm{Mn}_{2} \mathrm{Ge}_{2}$, and $\mathrm{PrMn}_{2-\mathrm{x}} \mathrm{Fe}_{\mathrm{x}} \mathrm{Ge}_{2}$ systems. The pressure produced by chemical substitution in these pseudo-ternaries is inherently non-uniform, with local pressure variations dependent on the local atomic distribution. We find that concentrated chemical substitution on the $R$ or $X$ site (e.g., in $\mathrm{Pr}_{0.5} \mathrm{Y}_{0.5} \mathrm{Mn}_{2} \mathrm{Ge}_{2}$ and $\mathrm{PrMn}_{2} \mathrm{Ge}_{0.8} \mathrm{Si}_{1.2}$ ) can produce a separation into two distinct magnetic phases, canted ferromagnetic and canted antiferromagnetic, with a commensurate phase gap in the crystalline lattice. This phase gap is a consequence of the combination of phase separation and spontaneous magnetostriction, which is positive on transition to the canted ferromagnetic phase and negative on transition to the canted antiferromagnetic phase. Our results show that co-existence of canted ferromagnetic and antiferromagnetic phases depends on chemical pressure from the rare earth and metalloid sites, on local lattice strain distributions and on applied magnetic field. We demonstrate that the effects of chemical pressure bear close resemblance to those of mechanical pressure on the parent compound. (C) 2014 AIP Publishing LLC.
\end{abstract}

[http://dx.doi.org/10.1063/1.4870582]

\section{INTRODUCTION}

The $\mathrm{RMn}_{2} \mathrm{X}_{2}$ series (where $\mathrm{R}$ is a rare earth and $\mathrm{X}$ is $\mathrm{Si}$ or $\mathrm{Ge}$ ) are layered intermetallic compounds in which the $\mathrm{R}$ and $\mathrm{Mn}$ atoms lie in alternate layers, separated by layers of $\mathrm{X}$ atoms. These compounds display a fascinating array of magnetic phases, due to the strong dependence of the $M n-M n$ magnetic exchange interaction on the intralayer near neighbour distance, and the interplay between the magnetism of the $3 d$ and $4 f$ layers. ${ }^{1}$ Magnetic phase transitions in these compounds are often accompanied by isostructural changes (strictions) due to the strong magnetoelastic coupling of both $\mathrm{R}$ and $\mathrm{Mn}$ sites. Up to eight different magnetic structures are observed for $M n-M n$ near neighbour distances in the range from $\sim 2.84 \AA$ to $\sim 2.92 \AA$, and it is possible to vary that distance by changing chemical composition or temperature and by applying mechanical pressure or a magnetic field. By systematic investigation of the influence of these variables on magnetic and atomic structure, we learn a great deal about the nature of these compounds and about their potential for technological applications.

\footnotetext{
a) Author to whom correspondence should be addressed. Electronic mail: sjk@ansto.gov.au.
}

Here. we report our findings on the pseudo-ternaries, $\mathrm{PrMn}_{2} \mathrm{Ge}_{2-\mathrm{x}} \mathrm{Si}_{\mathrm{x}}$ (Ref. 2), $\mathrm{Pr}_{1-\mathrm{x}} \mathrm{Y}_{\mathrm{x}} \mathrm{Mn}_{2} \mathrm{Ge}_{2}$ (Ref. 3), and $\mathrm{PrMn}_{2-\mathrm{x}} \mathrm{Fe}_{\mathrm{x}} \mathrm{Ge}_{2}$ (Ref. 4), derived from the parent compound $\mathrm{PrMn}_{2} \mathrm{Ge}_{2}$, (in which the Mn-Mn nearest neighbour distance is $2.915 \AA$ at room temperature), substituting for each constituent element with a smaller one to contract the lattice so as to observe the magneto-elastic transitions that occur as the $\mathrm{Mn}-\mathrm{Mn}$ nearest neighbour distance is reduced and to assess the role of Pr on the magnetism.

\section{EXPERIMENTAL DETAILS}

The synthesis of the compounds discussed here, $\operatorname{PrMn}_{2} \mathrm{Ge}_{2-\mathrm{x}} \mathrm{Si}_{\mathrm{x}}, \mathrm{Pr}_{1-\mathrm{x}} \mathrm{Y}_{\mathrm{x}} \mathrm{Mn}_{2} \mathrm{Ge}_{2}$, and $\mathrm{PrMn}_{2-\mathrm{x}} \mathrm{Fe}_{\mathrm{x}} \mathrm{Ge}_{2}$, have been described in Refs. 4-6.

It suffices to note here that all samples studied had been subjected to long annealing at high temperatures (typically above $900^{\circ} \mathrm{C}$ for at least 7 days) and were of high phase purity ( $98 \%$ or above).

Magnetization measurement, differential scanning calorimetry (DSC) measurements were performed at the Institute of Superconducting and Electronic Materials, University of Wollongong, in order to identify the magnetic phases and phase transition temperatures in these compounds. 
Neutron diffraction measurements variously evaluated here have been obtained at ANSTO on Wombat, Echidna, and Medium Resolution Powder Diffractometer (MRPD), at HZ-Berlin on E6, at ISIS on GEM, and at FRM-II on Spodi. Synchrotron X-ray diffraction experiments were performed at the powder diffraction beamline (PD) at the Australian Synchrotron.

\section{RESULTS AND DISCUSSION}

\section{A. Magnetic phases of $\mathrm{PrMn}_{2} \mathrm{Ge}_{2}$}

The magnetic properties of $\mathrm{PrMn}_{2} \mathrm{Ge}_{2}$ have been well reported $^{7-9}$ and will not be covered in detail here. Suffice to note that four magnetic phases have been observed, as depicted in Fig. 1, with transition temperatures of $105 \mathrm{~K}$, $286 \mathrm{~K}, 330 \mathrm{~K}$, and $420 \mathrm{~K}$ for $F m i+F P r, F m i, F m c$, and $A F l$ phases, respectively.

Primarily the magnetism is located in the planes of $\mathrm{Mn}$ atoms, which display planar antiferromagnetic order at all temperatures below $\mathrm{T}_{\mathrm{N}}(\sim 420 \mathrm{~K})$ and an additional axial ferromagnetic component below the transition between $A F l$ and $F m c$ phases $(\mathrm{T} \sim 330 \mathrm{~K})$. Pr orders ferromagnetically (with moments parallel to the ferromagnetic component of the $\mathrm{Mn}$ moments) at $\mathrm{T}_{\mathrm{C}(\mathrm{Pr})} \sim 105 \mathrm{~K}$.

Identification of these magnetic structures is made with neutron powder diffraction, as illustrated in Fig. 2, where we see a selected region of the diffraction pattern from $\mathrm{PrMn}_{2} \mathrm{Ge}_{2}$ between $4 \mathrm{~K}$ and $450 \mathrm{~K}$. For convenience, the magnetic phase transitions are marked on the plot. Most of the transitions are clear from changes in the diffraction pattern, and we note, in particular, the change in the position of the magnetic satellites of the incommensurate Fmi phase, around the (101) and (103) reflections, signifying a decrease in the period of rotation of the magnetic moments about the c-axis with increasing temperature.

\section{B. Pseudo-ternaries of $\mathrm{PrMn}_{2} \mathrm{Ge}_{2}$}

Mixing of any of the three constituent atoms of $\operatorname{PrMn}_{2} \mathrm{Ge}_{2}$ with a smaller atom invariably reduces the interatomic spacings, leading to modification of the magnetic structure. Typically, at a critical interatomic spacing $\left(\mathrm{d}_{\mathrm{Mn}-\mathrm{Mn}}\right.$ $=2.86 \AA$ ) where the axial component of the Mn-Mn magnetic exchange interaction changes sign, we observe a transition from $F m c$ to one in which the axial component of the
Mn moment couples antiferromagnetically between planes (denoted by $A F m c$ ). This change is independent of the nature of the substitution, being an essential feature of the electronic interactions between $\mathrm{Mn}$ atoms. We illustrate this point with the magnetic phase diagrams for $\operatorname{Pr}_{1-\mathrm{x}} \mathrm{Y}_{\mathrm{x}} \mathrm{Mn}_{2} \mathrm{Ge}_{2}$ (Fig. 3), and $\mathrm{PrMn}_{2-\mathrm{x}} \mathrm{Fe}_{\mathrm{x}} \mathrm{Ge}_{2}$ (Fig. 4), where the magnetic phase boundaries are drawn as a function of a lattice parameter to highlight the importance of interatomic spacing between nearest neighbour Mn atoms. Here, the lines of thermal expansion for specific values of substituent are kinked near the boundary between $A F m c$ and $F m c$ and in the region where Pr orders ferromagnetically.

The electronic origin of the boundary between $F m c$ and $A F m c$ magnetic states has been established by first principles calculations of the electronic structure of the two magnetic $\operatorname{states}^{3}$ using a spin polarized localized density approximation. Due to the anisotropic nature of the response of the lattice to changes in temperature and pressure, corresponding changes in the magnetic exchange energy of the two magnetic states $(F m c$ and $A F m c$ ) have different dependencies. Specifically, the calculations indicate that in $\operatorname{Pr}_{0.5} \mathrm{Y}_{0.5} \mathrm{Mn}_{2} \mathrm{Ge}_{2}$ the $F m c$ state is favoured at ambient pressure below $\sim 50 \mathrm{~K}$ and above $\sim 150 \mathrm{~K}$, whereas the $A F m c$ state is favoured between those temperatures, in agreement with our experimentally determined phase diagram (Fig. 3).

Experimentally, we observe that the boundary between $F m c$ and $A F m c$ is associated with a region of co-existence of both states. ${ }^{2}$ In neutron diffraction studies of the $\mathrm{PrMn}_{2} \mathrm{Ge}_{2-\mathrm{x}} \mathrm{Si}_{\mathrm{x}}$ series, we find that the transition from $A F l$ to either $F m c$ or $A F m c$ is also accompanied by spontaneous magnetostriction, which is positive on transition to $F m c$, and negative on transition to the $A F m c$ phase. ${ }^{2}$ Because of this magneto-elastic coupling co-existence of these two magnetic states is accompanied by a structural separation, such that a large "gap" $(\partial a / \bar{a} \approx 0.5 \%)$ appears in the phase diagram of $\mathrm{PrMn}_{2} \mathrm{Ge}_{2-\mathrm{x}} \mathrm{Si}_{\mathrm{x}}$. This gap, as shown in Fig. 3 of Ref. 2, appears to be temperature independent, extending all the way from $2 \mathrm{~K}$ to the transition to the $A F l$ state.

Identification of a phase gap in $\mathrm{PrMn}_{2} \mathrm{Ge}_{2-\mathrm{x}} \mathrm{Si}_{\mathrm{x}}$ prompts us to suggest that there will also be one in the shaded regions of Figs. 3 and 4 as well. Confirmation of this will require more detailed structural studies.

The appearance of a region of magnetic phase co-existence raises the question, as to why some crystallites

\section{Paramagnet}

$(P M)$

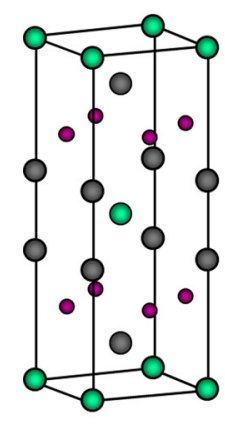

Planar antiferromagnet $(\boldsymbol{A F I})$

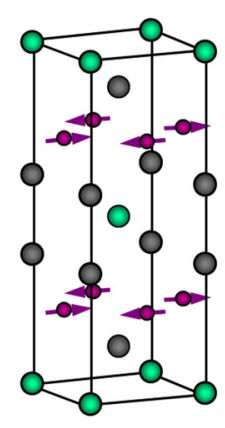

$A F L+$ axial ferromagnet (Fmc)

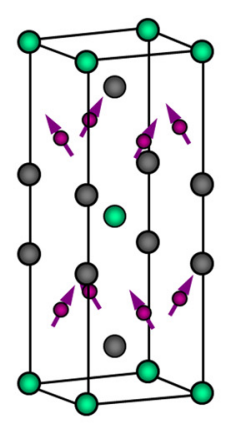

Incommensurate antiferromagnet (Fmi)

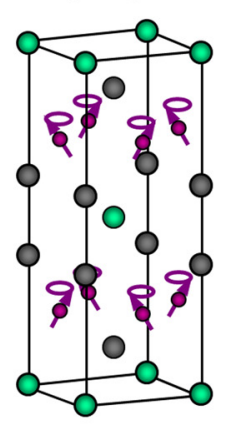

$F m i+\operatorname{Pr}$

ferromagnet

$\left(F m i+F_{P r}\right)$

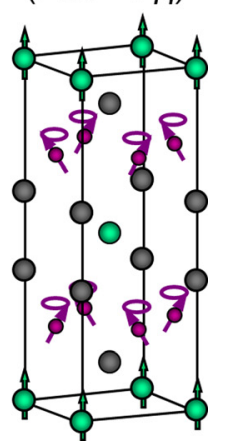

FIG. 1. Schematic of the magnetic structures found in $\mathrm{PrMn}_{2} \mathrm{Ge}_{2}$. $\mathrm{Pr}$ atoms are green, $\mathrm{Mn}$ atoms are maroon, and $\mathrm{Ge}$ atoms are grey. 


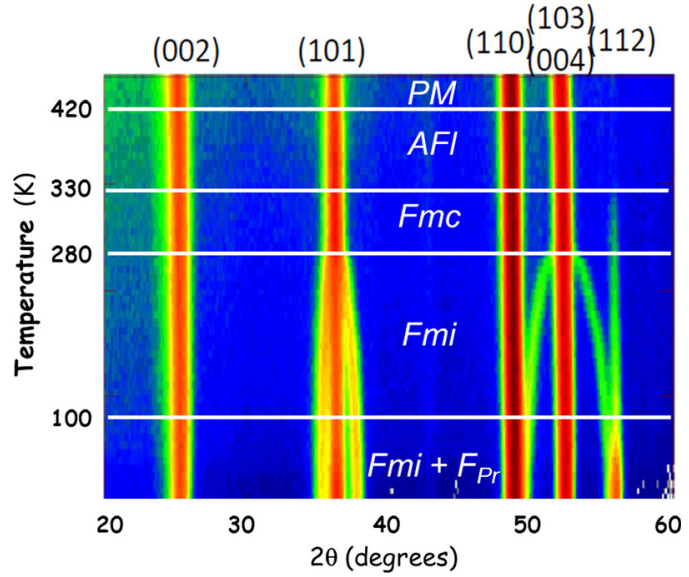

FIG. 2. Selected region of neutron powder diffraction patterns from $\mathrm{PrMn}_{2} \mathrm{Ge}_{2}$, showing four magnetic phase transitions between $4 \mathrm{~K}$ and $450 \mathrm{~K}$. (Data collected on the Wombat diffractometer at ANSTO.) The magnetic phases $F m i+F P r, F m i, F m c, A F l$, and PM are depicted in Fig. 1.

adopt the $F m c$ state whereas others adopt the $A F m c$ state. It is pertinent to add here that, to our knowledge, co-existence is only found in pseudo-ternary compounds and ternary compounds where the rare earth ion is suspected to be in a mixed valence state (as shown in Fig. 5 of Ref. 2).

We know from diffraction studies that there is no hint of long range chemical ordering on the mixed lattice site. Whether the chemical distribution is random or non-random is unclear from neutron diffraction. Certainly, considerable local lattice strain fields could be expected. ${ }^{10}$ Short range chemical order may also be present, and even the possibility of a miscibility gap is not excluded. Indeed strain can be seen in the neutron diffraction from $\operatorname{PrMn}_{2} \mathrm{Ge}_{2-x} \mathrm{Si}_{\mathrm{x}}$, even though instrumental factors dominate the measured peak widths. ${ }^{2,5}$ Concentration dependent lattice and magneto-elastic strain components can be identified in the (110) and (002) reflections. The lattice component, which is largely independent of temperature, is seen in both (110) and (002) reflections while the magneto-elastic component is

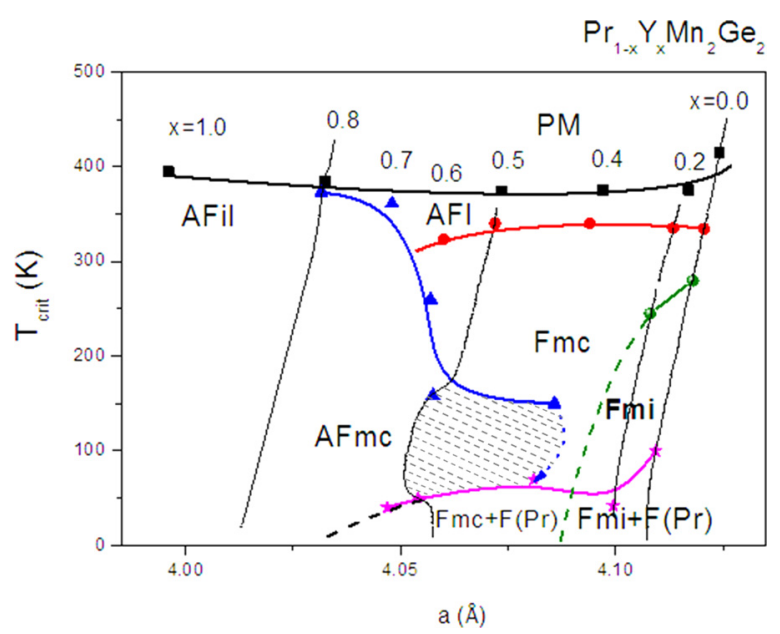

FIG. 3. Magnetic phase diagram of $\operatorname{Pr}_{1-x} \mathrm{Y}_{\mathrm{x}} \mathrm{Mn}_{2} \mathrm{Ge}_{2}$ as a function of a lattice parameter. Values of $\mathbf{x}$ are indicated above the line for Neel temperature $\left(\mathrm{T}_{\mathrm{N}}\right)$. Thermal expansion for selected concentrations of $\mathrm{Y}$ is indicated by fine black lines. The dashed line shows the extrapolated boundary between $F m c$ and Fmi.

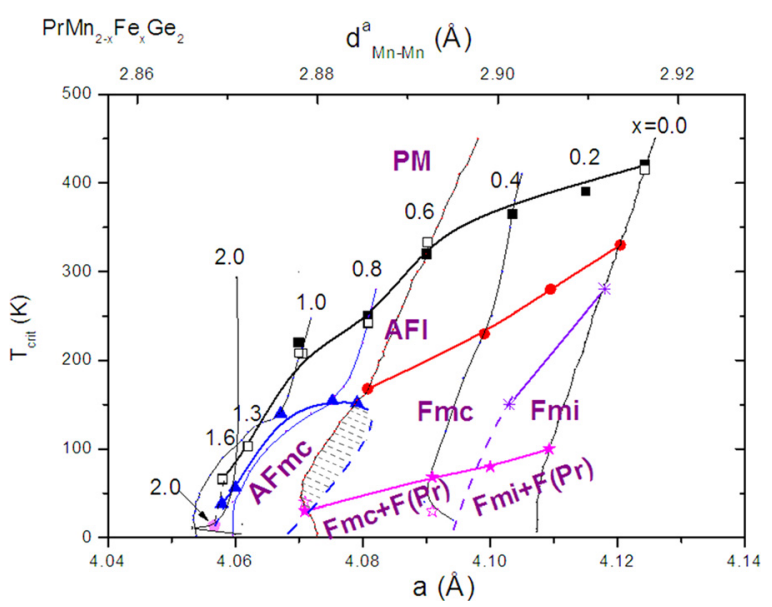

FIG. 4. Magnetic phase diagram of $\operatorname{PrMn}_{2-x} \mathrm{Fe}_{\mathrm{x}} \mathrm{Ge}_{2}$ as a function of a lattice parameter. Values of $\mathbf{x}$ are indicated above the line for Neel temperature $\left(\mathrm{T}_{\mathrm{N}}\right)$. Thermal expansion for selected concentrations of $\mathrm{Fe}$ is indicated by fine black lines.

evident only in the (110) reflection at $\mathrm{Ge} / \mathrm{Si}$ concentrations where $F m c$ and $A F m c$ co-exist.

\section{Magneto-structural anomalies}

High resolution scattering studies are needed to accurately determine strain distributions, domain sizes and the potential role of atomic short range order.

Our high resolution $\mathrm{X}$-ray powder diffraction study of the $\mathrm{PrMn}_{2} \mathrm{Ge}_{2-\mathrm{x}} \mathrm{Si}_{\mathrm{x}}$, series of compounds ${ }^{11}$ reveals many details of the structural features of these pseudo-ternaries. Most notably, we clearly see that chemical order is present in the $\mathrm{Ge} / \mathrm{Si}$ planes of all the pseudo-ternaries of this series, and that the lattice strain broadening is highly anisotropic. We illustrate this point in Fig. 5, which shows the (220) and (008) Bragg reflections from a pseudo-ternary $\left(\mathrm{PrMn}_{2} \mathrm{Ge}_{0.8} \mathrm{Si}_{1.2}\right)$ in which the two phase region is clearly seen. As in the neutron diffraction pattern of Fig. 2, the magnetic phase transitions are marked on the plot. Several features of note are; spontaneous magnetostriction can be seen at both the $A F l \leftrightarrow P M$ and $F m c / A F m c \leftrightarrow A F l$ phase boundaries, the magnetostriction at

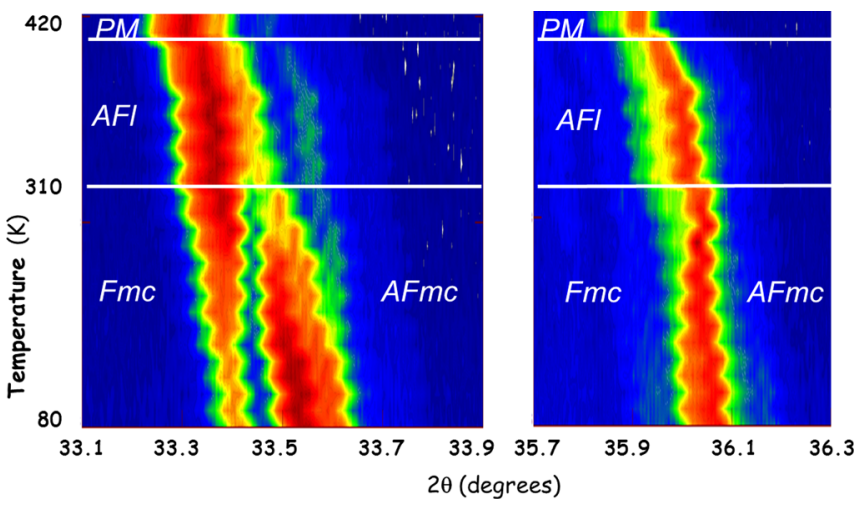

FIG. 5. Thermal dependence of the [220] (left) and [008] (right) X-ray Bragg peaks from $\mathrm{PrMn}_{2} \mathrm{Ge}_{0.8} \mathrm{Si}_{1.2}$, showing spontaneous magnetostriction at the magnetic phase transitions, and phase separation in the Fmc/AFmc region. Magnetic labels as above in Fig. 1, except $A F m c=A F l$ plus axial antiferromagnetic order. (Data collected on the PD beamline at the Australian Synchrotron.) 
the $A F m c \leftrightarrow A F l$ is of opposite sign to that of the $F m c \leftrightarrow A F l$ phase boundary, the (220) reflection is substantially broader than the (008) reflection, and whereas the (220) reflection is completely resolved into two peaks in the mixed Fmc/AFmc phase, the (008) reflection barely broadens. Thus, we see that one signature of the $A F m c$ phase is an increase in $\boldsymbol{c} / \boldsymbol{a}$ ratio. The variation in intensity of $F m c$ and $A F m c$ components of the (220) reflection indicate the changing concentration of the two phases, with $F m c$ dominating near $310 \mathrm{~K}$ and $A F m c$ dominating at $80 \mathrm{~K}$.

The anisotropic nature of the elastic response to the magnetic phase transitions is illustrated in the schematic (Fig. 6) of the crystal planes involved in the two reflections shown in Fig. 5. The substantial increase of the (220) peak angle in the $A F m c$ phase indicates drastic, uniform contraction of the $a-b$ plane, coupled with a mild contraction along the c-axis. Equally the broadness of the (220) reflection indicates large local atomic displacements in the $\boldsymbol{a}-\boldsymbol{b}$ plane, just as the relative narrowness of the (008) reflection indicates rather minor local atomic displacements in the direction of the $\mathrm{c}$ axis.

Close examination of the high resolution X-ray diffraction patterns of the $\operatorname{PrMn}_{2} \mathrm{Ge}_{2-\mathrm{x}} \mathrm{Si}_{\mathrm{x}}$, series collected at $450 \mathrm{~K}$ reveals a separation into two distinct phases in all of the pseudo-ternaries. Since this is seen in the paramagnetic phase it cannot be related to the magnetic order and must therefore be chemical in nature. Rietveld analysis of these diffraction patterns provides further insights. These are summarized in Figs. 7(a)-7(c), where the two phases are denoted as $\mathrm{Si}$ rich (with blue symbols) and $\mathrm{Ge}$ rich (with orange symbols).

Both a and $\mathbf{c}$ lattice parameters and the $\mathrm{Si} / \mathrm{Ge}$ concentration were fitted in the Rietveld refinement process. The concentration dependence of the lattice parameters (Fig. 7(a)) shows a displacement to the left for the Ge rich phase and to the right for the Si rich phase. Although the slope of the concentration dependence of lattice parameters for the two phases is not identical they are quite close to each other, and to the value predicted by Vegard's law (indicated by full and
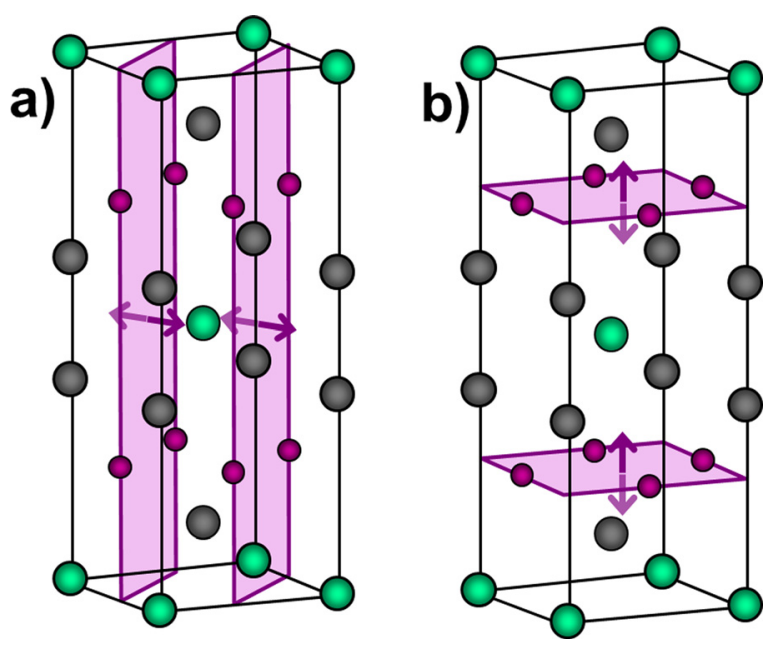

FIG. 6. Schematic of selected crystal planes (a) (220) and (b) (002) planes. In each case, only the planes containing $\mathrm{Mn}$ atoms (maroon colour) are indicated.

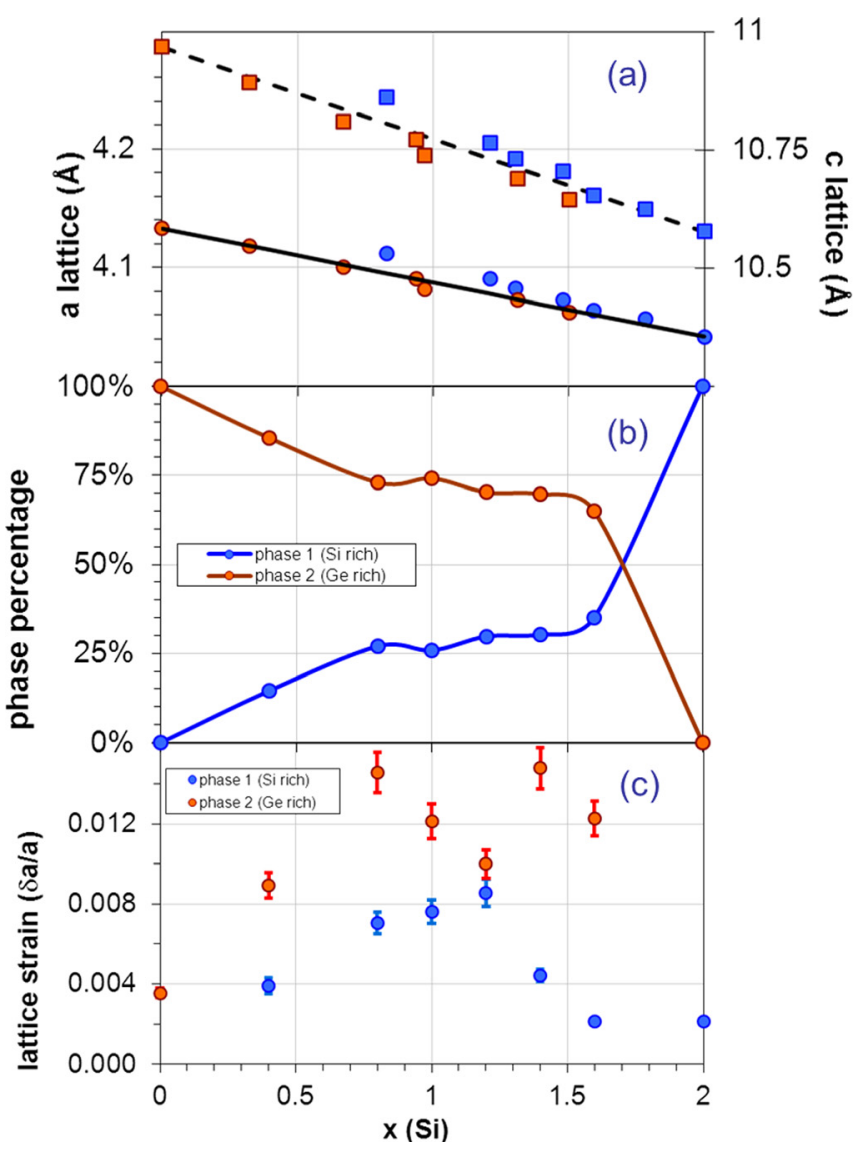

FIG. 7. (a) Lattice parameters in paramagnetic phase of $\operatorname{PrMn}_{2} \mathrm{Ge}_{2-x} \mathrm{Si}_{x}$, $(\mathrm{T}=450 \mathrm{~K})$ (the full and dashed lines show concentration dependence expected due to Vegard's Law), (b) percentages of $\mathrm{Si} / \mathrm{Ge}$ rich phases shown in (a), and (c) lattice strain in each phase. In each plot, the blue/orange symbols denote $\mathrm{Si} / \mathrm{Ge}$ rich phases, respectively.

dashed lines in Fig. 7(a)). The relative concentration of the two phases (shown in Fig. 7(b)) changes sharply for $\mathbf{x} \leq 0.8$, but then appears to be relatively constant at $\sim 75 \%$ of the Ge rich phase and $\sim 25 \%$ of the Si rich phase for all higher concentrations of $\mathrm{Si}$. This rather surprising result indicates that the difference between $\mathrm{Si} / \mathrm{Ge}$ concentration of the two phases remains relatively constant across the series. Finally, the lattice strain (shown in Fig. 7(c)) is high even in the end compounds $\left(\mathrm{PrMn}_{2} \mathrm{Ge}_{2}\right.$ and $\left.\mathrm{PrMn}_{2} \mathrm{Si}_{2}\right)$ and is greater in the Ge rich phase than the Si rich phase, increasing to quite large values around $\mathbf{x}=1$.

\section{Effect of mechanical pressure}

Thus, far we have considered the effect of chemical distributions on the magnetic and structural properties. We now consider the effect of mechanical pressure.

Fig. 8 shows the measured pressure dependence of lattice volume (Fig. 8(a)) and $\boldsymbol{c} / \boldsymbol{a}$ ratio (Fig. 8(b)) for three compounds in this series. The data were obtained by X-ray diffraction on the PD beamline at the Australian Synchrotron, using a diamond anvil pressure cell. ${ }^{12}$ The compressibility of $\mathrm{PrMn}_{2} \mathrm{Ge}_{2}$ is noticeably greater than $\operatorname{Pr}_{0.5} \mathrm{Y}_{0.5} \mathrm{Mn}_{2} \mathrm{Ge}_{2}$ and $\mathrm{PrMn}_{2} \mathrm{Si}_{2}$, particularly at lower pressures. We note that both $\mathrm{PrMn}_{2} \mathrm{Ge}_{2}$ and $\mathrm{Pr}_{0.5} \mathrm{Y}_{0.5} \mathrm{Mn}_{2} \mathrm{Ge}_{2}$ adopt the Fmc state at 


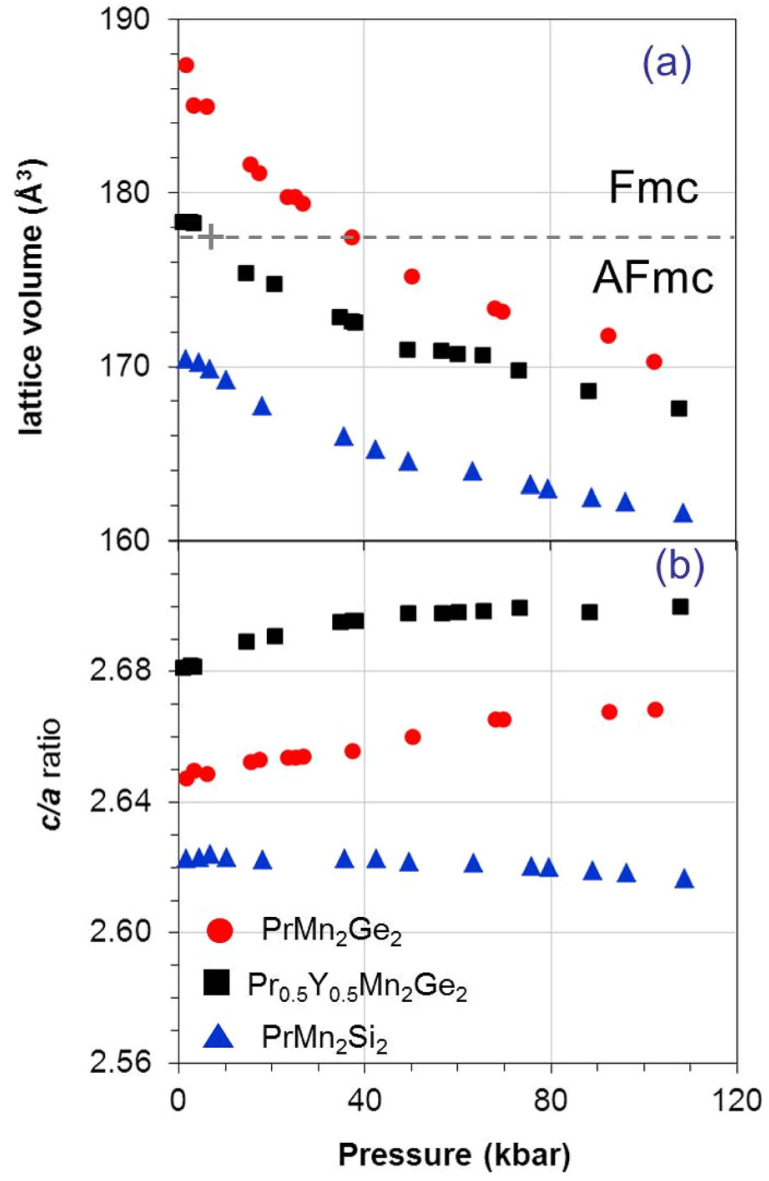

FIG. 8. Plot of (a) change in lattice volume and (b) change in c/a ratio in response to applied "mechanical" pressure for $\operatorname{PrMn}_{2} \mathrm{Ge}_{2}, \mathrm{Pr}_{0.5} \mathrm{Y}_{0.5} \mathrm{Mn}_{2} \mathrm{Ge}_{2}$, and $\mathrm{PrMn}_{2} \mathrm{Si}_{2}$ (at room temperature). The grey dashed line in Fig. 8(a) indicates the critical volume where the $F m c \leftrightarrow A F m c$ transition may be expected.

ambient temperature and pressure, whereas $\mathrm{PrMn}_{2} \mathrm{Si}_{2}$ is in the $A F m c$ state.

We also note from the report of pressure dependence of magnetization in $\operatorname{Pr}_{0.5} \mathrm{Y}_{0.5} \mathrm{Mn}_{2} \mathrm{Ge}_{2}$ (Ref. 3) that the critical pressure for the $F m c \leftrightarrow A F m c$ transition occurs at $\mathrm{P} \sim 6.7$ kilobars, as indicated by the grey cross in Fig. 8(a). Taking this as a general indication of critical volume for the $F m c \leftrightarrow A F m c$ transition, we deduce that the critical pressure for the transition in $\operatorname{PrMn}_{2} \mathrm{Ge}_{2}$ lies at $\mathrm{P} \sim 38$ kilobars.

This interpretation is well supported by the trends in c/a ratios (Fig. 8(b)), where we see a pronounced increase in the c/a ratio of $\mathrm{Pr}_{0.5} \mathrm{Y}_{0.5} \mathrm{Mn}_{2} \mathrm{Ge}_{2}$ from very low pressure and an increase in slope of the $\boldsymbol{c} / \boldsymbol{a}$ ratio for $\mathrm{PrMn}_{2} \mathrm{Ge}_{2}$ at $\mathrm{P}=38$ kilobars. In contrast, the $\boldsymbol{c} / \boldsymbol{a}$ ratio of $\mathrm{PrMn}_{2} \mathrm{Si}_{2}$, which is in the $A F m c$ state under ambient conditions, does not increase with pressure.

\section{E. Comparison of chemical and mechanical pressure}

In order to compare the effects of mechanical pressure with those of chemical distributions, we describe the lattice response to pressure with the equation of state whereby, the bulk modulus $(B)$ describes the change in volume $(V)$ of a solid in response to pressure $(P)$

$$
B=-V\left(\frac{\delta P}{\delta V}\right)_{T}
$$

Defining $\left(B^{\prime}\right)$ to describe the pressure dependence of the bulk modulus, such that

$$
B^{\prime}=\left(\frac{\delta B}{\delta P}\right)_{T}
$$

In practice $B^{\prime}$ is generally constant and can be reduced to $B_{o}^{\prime}$, so we can write

$$
B=B_{o}+B_{o}^{\prime} P,
$$

where $B_{o}$ is $B$ at ambient pressure, and we can integrate Eq. (1) to give

$$
P(V)=\frac{B_{o}}{B_{o}^{\prime}}\left(\left(\frac{V_{o}}{V}\right)^{B_{o}^{\prime}}-1\right),
$$

or equivalently

$$
V(P)=V_{o}\left(1+B_{o}^{\prime} \frac{P}{B_{o}}\right)^{-1 / B_{o}^{\prime}},
$$

where $V_{o}$ is the volume of the solid at ambient pressure.

We have applied Eq. (4a) to our room temperature diffraction data with values of $B_{o}$ and $B_{o}^{\prime}$ from a closely related compound $\left(\mathrm{UGe}_{2} \mathrm{Mn}_{2}\right)$ (Ref. 13) to derive the equivalent "chemical pressure" from our three series of pseudo-ternary compounds.

The results are summarized in Fig. 9, where we plot chemical pressure against substituent concentration (x). The dashed lines in Fig. 9 broadly indicate the slope of chemical pressure for each compound, and highlight the transition at $\mathrm{x}=0.5$, which marks the boundary between $F m c$ and $A F m c$ magnetic state in $\operatorname{Pr}_{1-\mathrm{x}} \mathrm{Y}_{\mathrm{x}} \mathrm{Mn}_{2} \mathrm{Ge}_{2}$ (Ref. 3) and $\operatorname{PrMn}_{2}\left(\mathrm{Ge}_{1-\mathrm{x}} \mathrm{Si}_{\mathrm{x}}\right)_{2}$ (Ref. 2).

For those compounds, we see a marked increase in compressibility in the $A F m c$ phase. In contrast, $\operatorname{Pr}\left(\mathrm{Mn}_{1-\mathrm{x}} \mathrm{Fe}_{\mathrm{x}}\right)_{2} \mathrm{Ge}_{2}$

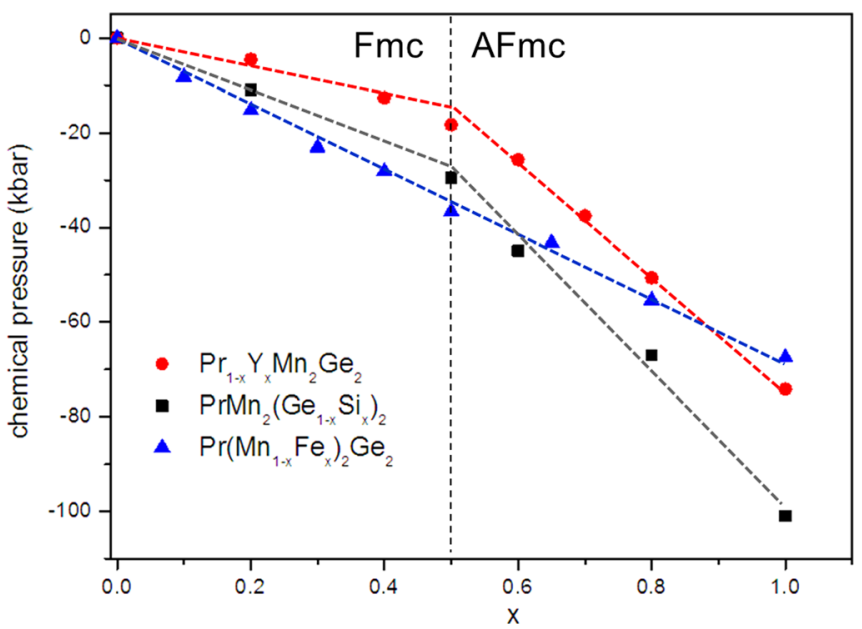

FIG. 9. Plot of "chemical pressure" against substituent concentration (x) for $\mathrm{Y}, \mathrm{Fe}$, and $\mathrm{Si}$ substitution in $\mathrm{PrMn}_{2} \mathrm{Ge}_{2}$. 
undergoes a magnetic transition from $F m c$ to $A F l$ near $\mathrm{x}=0.1$ and another to $P M$ near $\mathrm{x}=0.7$. Clearly, neither magnetic transition affects the compressibility of the $\operatorname{Pr}\left(\mathrm{Mn}_{1-\mathrm{x}} \mathrm{Fe}_{\mathrm{x}}\right)_{2} \mathrm{Ge}_{2}$ compound.

The initial slope of the change in chemical pressure with concentration reflects the magnitude of response to the mismatch between atom sizes in the mixed lattice plane, in the absence of any magnetic transition. For $\operatorname{Pr}_{1-\mathrm{x}} \mathrm{Y}_{\mathrm{x}} \mathrm{Mn}_{2} \mathrm{Ge}_{2}$ and $\operatorname{PrMn}_{2}\left(\mathrm{Ge}_{1-\mathrm{x}} \mathrm{Si}_{\mathrm{x}}\right)_{2}$, the initial slope is roughly in proportion to the relative sizes of the ions in the mixed plane (i.e., $\mathrm{Y}^{3+}$ is $\sim 10 \%$ smaller than $\operatorname{Pr}^{3+}$ and $\mathrm{Si}^{4+}$ is $\sim 25 \%$ smaller than $\mathrm{Ge}^{4+}$ ). It is perhaps surprising that substitution of Fe for Mn, where the electron density distribution is only slightly more compact, applies by far the strongest chemical pressure. It may be that dilution of the Mn-Mn exchange interaction with increasing $\mathrm{Fe}$ concentration produces an effective increase in compressibility.

Finally, we compare the relative efficiencies of mechanical and chemical pressure on $\mathrm{PrMn}_{2} \mathrm{Ge}_{2}$. Although Fig. 9 indicates that the magnetic $F m c \leftrightarrow A F m c$ transition in $\operatorname{Pr}_{1-\mathrm{X}} \mathrm{Y}_{\mathrm{X}} \mathrm{Mn}_{2} \mathrm{Ge}_{2}$ and $\operatorname{PrMn}_{2}\left(\mathrm{Ge}_{1-\mathrm{X}} \mathrm{Si}_{\mathrm{X}}\right)_{2}$ occurs around $\mathrm{x}=0.5$, we note that both $\operatorname{Pr}_{0.5} \mathrm{Y}_{0.5} \mathrm{Mn}_{2} \mathrm{Ge}_{2}$ and $\operatorname{PrMn}_{2} \mathrm{GeSi}$ actually display mixed $F m c / A F m c$ character at room temperature, and the boundary is not sharp. The chemical boundary for complete conversion to the AFmc magnetic state at room temperature is closer to $\operatorname{Pr}_{0.4} \mathrm{Y}_{0.6} \mathrm{Mn}_{2} \mathrm{Ge}_{2}$ (see Fig. 3) and $\mathrm{PrMn}_{2} \mathrm{Ge}_{0.6} \mathrm{Si}_{1.4}$ (Ref. 2), corresponding to chemical pressure of $\mathrm{P} \sim 27$ kilobars (for $\mathrm{Y}$ substitution) and 55 kilobars (for $\mathrm{Si}$ substitution). These pressures are comparable to our critical value of $\mathrm{P} \sim 38$ kilobars for applied mechanical pressure. Given the coarseness of our experimental data (in terms of chemical substitution), this result is in good agreement with our comparison of the rate of change of Pr ordering temperature $\left(\mathrm{T}_{\mathrm{C}}{ }^{\mathrm{Pr}}\right),{ }^{3}$ which indicates that mechanical pressure is a more efficient driver of the Fmc to AFmc magnetic transition than chemical pressure. If indeed chemical pressure is less effective, it may derive from the enhanced local strain distribution and phase separation which accompanies chemical substitution.

\section{CONCLUSIONS}

We have shown that the two phase region in the $\operatorname{PrMn}_{2} \mathrm{Ge}_{2-\mathrm{x}} \mathrm{Si}_{\mathrm{x}}, \operatorname{Pr}_{1-\mathrm{x}} \mathrm{Y}_{\mathrm{x}} \mathrm{Mn}_{2} \mathrm{Ge}_{2}$, and $\operatorname{PrMn}_{2-\mathrm{x}} \mathrm{Fe}_{\mathrm{x}} \mathrm{Ge}_{2}$ series of compounds is associated with chemical phase separation due to chemical distributions at the mixed site. We have also shown that chemical substitution produces large local strain distributions, mainly in the $\boldsymbol{a}-\boldsymbol{b}$ planes. Finally, we have shown that these compounds all share a common magnetic character, dependent mainly on the $\mathrm{Mn}-\mathrm{Mn}$ interatomic distance, regardless of which site bears the substituent atoms, and that this character is broadly consistent with the effect of mechanical pressure.

\section{ACKNOWLEDGMENTS}

We wish to thank Andrew Studer (ANSTO), Zhengxiang Cheng and Muhamad Faiz Md Din (ISEM, Wollongong), Luana Caron and Ekkes Brück (TU-Delft), and Qinfen $\mathrm{Gu}$ and Helen Brand (Australian Synchrotron), for their valuable contributions to this research.

We also acknowledge the Australian Research Council (ARC), the Australian Institute of Nuclear Science and Engineering (AINSE), and the Access to Major Research Facilities Program (AMRFP) for their sustained financial support.

\footnotetext{
${ }^{1}$ A. Szytula, in Handbook of Magnetic Materials, edited by K. H. J. Buschow (Elsevier, Amsterdam, 1991), Vol. 6, Chap. 2.

${ }^{2}$ J. L. Wang, S. J. Kennedy, S. J. Campbell, M. Hofmann, and S. X. Dou, Phys. Rev. B 87, 104401 (2013).

${ }^{3}$ J. L. Wang, L. Caron, S. J. Campbell, S. J. Kennedy, M. Hofmann, Z. X. Cheng, M. F. Md Din, A. J. Studer, E. Bruck, and S. X. Dou, Phys. Rev. Lett. 110, 217211 (2013).

${ }^{4}$ J. L. Wang, S. J. Campbell, A. J. Studer, M. Avdeev, M. Hofmann, M. Hoelzel, and S. X. Dou, J. Appl. Phys. 104, 103911 (2008).

${ }^{5}$ J. L. Wang, S. J. Campbell, M. Hofmann, S. J. Kennedy, and S. X. Dou, J. Phys.: Condens. Matter 25, 386003 (2013).

${ }^{6}$ J. L. Wang, S. J. Campbell, J. M. Cadogan, A. Studer, R. Zeng, and S. X. Dou, Appl. Phys. Lett. 98, 232509 (2011).

${ }^{7}$ A. Szytula and I. Szott, Solid State Commun. 40, 199 (1981).

${ }^{8}$ N. Iwata, T. Ikeda, T. Shigeoka, H. Fujii, and T. Okamoto, J. Magn. Magn. Mater. 54-57, 481 (1986).

${ }^{9}$ R. Welter, G. Venturini, E. Ressouche, and B. Malaman, J. Alloys Compd. 218, 204 (1995).

${ }^{10}$ P. Singh and S. Prakash, Phys. Rev. B 59, 14226 (1999).

${ }^{11}$ J. L. Wang, S. J. Kennedy, Q. F. Guo, S. J. Campbell, and S. X. Dou, "Identification of binary phase nature of pseudo-ternary $\operatorname{PrMn}_{2} \mathrm{Ge}_{2-\mathrm{x}} \mathrm{Si}_{\mathrm{x}}$ compounds," (unpublished).

${ }^{12}$ J. L. Wang, S. J. Kennedy, H. Brand, S. J. Campbell, and S. X. Dou, "Magnetoelastic response of $\operatorname{Pr}_{1-\mathrm{y}} \mathrm{Y}_{\mathrm{y}} \mathrm{Mn}_{2} \mathrm{Ge}_{2-\mathrm{x}} \mathrm{Si}_{\mathrm{x}}$ compounds to mechanical pressure," (unpublished).

${ }^{13}$ V. Siruguria, S. K. Paranjpe, P. Raj, A. Sathyamoorthy, J.-P. Itie, and A. Polian, Physica B 344, 255 (2004).
} 